\title{
Delayed childbearing in contemporary Spain: trends and differentials
}

\author{
Teresa Castro Martín
}

United Nations *, New York, USA

Received 23 August 1991; final version received 5 February 1992

Castro Martín, T., 1992. Delayed childbearing in contemporary Spain: trends and differentials. European Journal of Population/Revue Européenne de Démographie, 8: $217-246$.

\begin{abstract}
During the last decade, family formation patterns in Spain have undergone a process of substantial transformation. Younger cohorts are increasingly postponing marriage and, once they enter marriage, they tend to delay childbearing. Partly as a result of these timing shifts, period measures such as total fertility rates are likely to underestimate "true" fertility levels. This study focuses on the first stage of family formation: the transition to motherhood. Following a birth interval approach, the analysis depicts recent trends and differentials in the timing of first birth and explores the role of premarital pregnancies and contraceptive practice on first interval dynamics.
\end{abstract}

Castro Martín, T., 1992. Délais dans la procréation en Espagne contemporaine: tendances et différences (en anglais). European Journal of Population/Revue Européanne de Démographie, 8: 217-246.

Résumé Durant la dernière décennie en Espagne, les types de constitution de la famille ont connu de substantielles transformations. Les plus jeunes cohortes prolongent leur célibat et, une fois mariées, tendent à retarder leurs naissances. En partie comme un effet de ces changements temporels, les mesures transversales, telles que la fécondité cumulée, sous-estiment vraisemblablement les "vrais" niveaux de la fécondité. Cette étude concentre son attention sur la prémière étape de la formation des

* The views expressed in this article are those of the author and do not necessarily represent those of the United Nations.

Correspondence to: T. Castro Martin, Population Division, United Nations, DC2-2056, 2 United Nations Plaza, New York, NY 10017, USA. 
familles: la transition vers la maternité. En utilisant une approche longitudinale, on analyse les tendances et les différences dans le calendrier de la première naissance et l'on explore le rôle des grossesses prémaritales et des pratiques contraceptives sur la dynamique de l'intervalle entre mariage et première naissance.

\section{Introduction}

The traditional distinction between low-fertility Northern Europe and high-fertility Southern Europe (Blayo, 1987; Muñoz-Pérez, 1987) has been recently inverted: in 1989, Sweden (with a TFR of 2.02), Norway (1.84) and the United Kingdom (1.85) had higher fertility than Portugal (1.53), Greece (1.50), Spain (1.30) or Italy (1.29, the world's lowest level) (Monnier, 1990). Breaking a pattern that had prevailed for a long historical period, Spain's total fertility rate reached 1.3 children per woman in 1989 , a level considerably lower than that of her Northern neighbours.

The unprecedented low fertility reached by Spain is likely to arouse some scepticism. After all, Spain's level of economic development and social welfare ranks below Northern Europe's, the integration of women into the labour force is far from complete, historical ties to a Catholic tradition still influence the normative context, and only two decades ago the country was under a totalitarian political regime that endorsed a pronatalist ideology and outlawed contraception.

Though it is unquestionable that Spain has experienced a considerable fertility reduction (Sáez, 1979; Agüero and Olano, 1980; Díez Nicolás and de Miguel, 1981; Fernández Cordón, 1986; Arango, 1987), especially during the last decade (Hicks and Martínez-Aguado, 1987; Delgado Pérez and Fernández Cordón, 1989), the magnitude of the descent is likely to have been overestimated, owing to the confluence of quantum (completed cohort fertility) and tempo (birth timing) changes in the process of reproduction.

As is well established, synthetic fertility rates are subject to distortions when the schedule of family building experiences changes (Ryder, 1980). The recent demographic trajectory of Northern Europe offers a good illustration of the linkage between shifts in reproductive timing and fluctuations in period fertility rates. The low fertility rates recorded in the Scandinavian countries during the $1970 \mathrm{~s}$, for example, were partly due to a pattern of delayed childbearing. The trend, however, 
reversed in the 1980s and fertility rates rose again as postponed births were "made up" at older ages. By the same token, the exceptionally low fertility level currently recorded in Spain is partly attributable to changing family formation patterns among young generations, in particular the postponement of marriage and the deferment of first births.

As small families become the norm, parity-specific measures become more suitable than age-specific measures for grasping fertility trends, and the pace of family formation becomes more relevant than an increasingly homogeneous completed family size in determining natality levels. Following a sequential and dynamic approach to fertility analysis (e.g. Ryder, 1982; Tsui, 1982; Feeney, 1983), this study focuses on the initial stage of the family building process: the transition to first birth. The timing of motherhood is relevant not only because of its repercussions on the societal level of reproduction, but because it constitutes a major and qualitatively unique life transition. At the family level, the arrival of a child transforms the economic and social world of the couple, and its timing sets the context of subsequent childbearing performance (Bumpass et al., 1978). At the individual level, the timing of a woman's first birth has important implications for her subsequent life options (Hoffert, 1984; Walter, 1986).

The paper is organized as follows: first, we will document the recent trend towards delayed motherhood in Spain; next, we will identify some of the sociodemographic factors that are associated with the current pattern of postponed childbearing. The role of premarital pregnancies and contraceptive practice on first interval dynamics will be also discussed.

\section{Data and definitions}

The analysis is based on data from the 1985 Spanish Survey of Fertility, a nationally representative sample of 8,782 women aged 18 to 49 , conducted by the Spanish National Institute of Statistics.

For the purpose of this paper, first birth timing is operationalized as first interval length, defined as the time elapsed between marriage and first live birth. Marriage has become an increasingly poor indicator of the onset of sexual activity and therefore can no. longer be regarded as an adequate marker of the beginning of exposure to the 
risk of conception. However, we can still use marriage as a socially defined reference point from which to establish inter-cohort comparisons of the time pattern of transition to first birth.

Premarital births $(2.7 \%$ of first births) are excluded from the analysis. Not only do they imply "negative" intervals that would pose practical computational problems, but they are likely to respond to different determinant factors. Premarital conceptions also violate the sequence marriage-conception-birth conventionally assumed. (A birth occurring seven or fewer months following marriage is assumed to be premaritally conceived, though in some cases we might be confounding premature births or reporting errors in event dates). Furthermore, the underlying causal process is reversed, since the timing of conception conditions the timing of marriage and not vice versa. However, since they constitute a substantial proportion of marital first births, an analysis of the transition to first birth conditional on not having experienced a premarital conception would not be representative of all women entering motherhood. We have opted to present models including and excluding premarital conceptions, in order to assess their role on the aggregate trend of first interval length. The methodological strategy chosen will allow us to differentiate the determinants of premaritally and maritally conceived first births.

\section{Methods of analysis}

The description of trends and differentials is based on life table estimates. Life table techniques allow us to incorporate into the analysis the exposure of women who did not experience the transition to first birth by the survey date (censored observations), and thus avoid the bias towards shorter durations inherent in closed intervals (Hobcraft and Rodríguez, 1980; Namboodiri and Suchindran, 1987).

The multivariate analysis is based on hazard models, which combine the principles of life tables with a regression-like framework (for review, see Hobcraft and Murphy, 1986; Palloni and Sorensen, 1986). Hazard models have been widely applied to birth interval analysis (e.g. Rodríguez et al, 1984; Newman and McCulloch, 1984; Lamas, 1985; Trussell et al, 1985; Gilks, 1986; Moreno-Navarro, 1987). The Cox proportional hazard model (Cox, 1972), which focuses exclusively on the effect of the covariates, leaving unspecified the duration function 
of the process, is the most widely used. It can be formulated as follows:

$$
h(t ; X)=h_{0}(t) e^{\beta X}
$$

where $h(t ; \boldsymbol{X})$ denotes the hazard rate of transition to first birth at duration $t$ for a woman with a vector of covariates $X ; h_{0}(t)$ denotes the baseline hazard function corresponding to the reference group; and $\beta$ is a vector of regression-like coefficients, which quantify to what extent the covariates shift, upward or downward, the underlying baseline hazard. The exponential form of the coefficients $\left(e^{\beta}\right)$, or relative risks, express the effect of the covariates as proportionate increases or reductions in childbearing risks. Since most women eventually become mothers, lower or higher "risks" of childbearing indicate slower or faster pace of transition to first birth. (In higher-order intervals, the substantive meaning of "risk" is not so clear-cut, since timing variations coexist with different rates of birth progression.)

Though proportional hazard models have many attractive properties and their results can be easily interpreted, the underlying assumption of proportionality (i.e. that the risk differential between subgroups is constant throughout duration) might not be appropriate for representing the process of transition to first birth. If eventually most women become mothers, differentials will be mainly built on timing patterns. And to the extent that the postponement of the first child is not definitive, women who are "delayers" and have low birth transition rates at early marital durations will probably display higher transition rates at later durations. As a consequence of this "compensating" mechanism, duration-varying effects are likely to be inherent in the process.

Discrete-time hazard models provide a more flexible tool of analysis, since they allow incorporation of the interactions between covariates and duration and hence the handling of non-proportional effects (Allison, 1982). This approach is particularly appropriate to model the first birth transition, a process in which subgroup differentials are likely to vary across marital duration. Also, since the effect of the covariates is evaluated separately within each duration segment, this modelling strategy allows us to differentiate the factors that predispose to premarital conception and the factors that influence the timing of maritally conceived births in a single model. 
In order to simplify the calculations, we used a piecewise constant hazard model, which assumes that the transition rate is constant within each duration segment, though it can vary between segments (e.g. Hoem, 1985). The following grouping of marital duration was adopted: $0-7$ (to capture premarital pregnancies), 8-12, 13-18, 19-24, 25-36 and 37-48 months. To construct the file for discrete hazard analysis, a sub-file for each duration segment was prepared, including only those women exposed to the risk of transition at the beginning of the segment. All the segments were then pooled together and analyzed simultaneously. Hazard models were estimated in GLIM (Baker and Nelder, 1978; Aitkin and Clayton, 1980). The pooling of personsegments results in a number of units of analysis much higher than the original number of respondents, which tends to exaggerate the apparent degrees of freedom. In addition, when using multiple observations for each individual, unobserved sources of variation may inject some serial correlation into the error term, leading to underestimation of standard errors. Though this procedure has no biasing effect on the coefficients (Allison, 1982), caution is recommended when interpreting parameter estimates that are only marginally significant.

\section{Trends in the timing of transition to first birth}

Traditionally, marriage and the onset of reproduction have been closely interconnected in Spain. Given the prior historical context characterized by marginal participation of women in the labour market, difficult access to contraception and norms prescribing family-oriented female roles, this linkage is not surprising. However, we expect to find substantial changes in the reproductive behaviour of recent cohorts. Most societal trends, such as recent contraceptive availability, increased female education and labour force participation (Alcobendas, 1984), as well as attitudinal changes regarding the roles socially assigned to women, lead us to expect an increasing postponement of motherhood.

As predicted, the data reveal that age of entry into motherhood has been rising substantially during the last decade. Life table estimates indicate that the median age of women at first birth rose from 24.6 in the late 1970 s to 25.6 in the early $1980 \mathrm{~s}$. A substantial part of this increase can be attributed to a pattern of later marriage, but the 
expanded interval between marriage and first birth is also likely to have played an important role.

To describe trends in first birth timing, we will contrast the reproductive experience of successive marriage cohorts. The reconstruction of historical trends from cross-sectional fertility surveys faces a selectivity problem because of the restriction of the sample to women of childbearing age. Earlier marriage cohorts are increasingly biased towards younger ages at marriage (for instance, women married at ages 30-34 in the period 1965-69 fall outside the sampling frame, since they were 50-54 years old at the interview date), and to the extent that age at marriage is inversely related to the speed of transition to first birth, this truncation may produce an artifactual trend towards first interval lengthening (Rindfuss et al., 1982). In order to avoid this selectivity bias, we have restricted the analysis to women married before age 30 in the period 1965-83. Even if selectivity bias were not present, the reporting of birth events is likely to become increasingly inexact with time, making it problematic to include older cohorts.

Fig. 1 illustrates the pace of transition to first birth for four consecutive marriage cohorts in terms of life-table quartiles. Though the median waiting time to motherhood has not changed much during this period, a wider dispersion in first birth timing can be observed in recent times (the interquartile range was 14 months for the 1970-74 cohort, but 26 months for the 1980-83 cohort). Women married in the late 1960 s and early 1970 s were a relatively homogeneous group in terms of their rapid transition to motherhood: half of them became mothers in the first year of marriage, and $75 \%$ by the second year of marriage. Among later cohorts, the variation is much greater: though a substantial number of women continue to bear their first child right after marriage, a significant proportion delays this transition. It is not until the third year of marriage that $75 \%$ of the women married in the early 1980 s become mothers, one year later than the preceding cohorts.

Fig. 2 shows the cumulative proportion of women who have made the transition to first birth, evaluated at successive marital durations. Three major features emerge from the examination of this graph. First, the ultimate incidence of motherhood remains practically unchanged during the period under examination. Accordingly, intercohort differentials can be presented exclusively in terms of timing. 


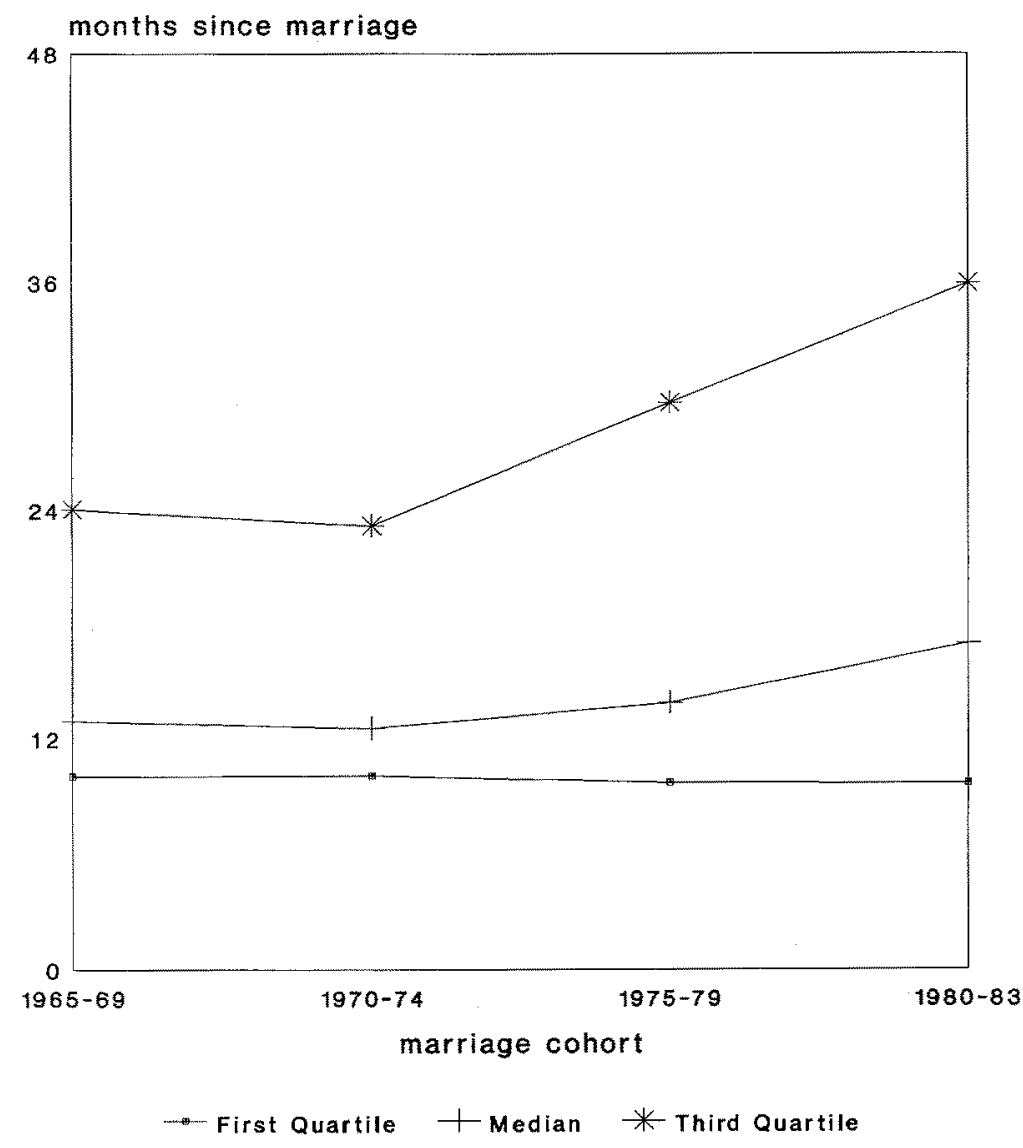

Fig. 1. Life-table quartiles of the length of the first birth interval for successive marriage cohorts.

Second, as we pointed out earlier, the trend towards first birth postponement is manifest only after 1975 . Third, differentials do not remain constant across marital duration. The most recent marriage cohort, for instance, displays the highest proportion of women who become mothers within the initial seven months of marriage, and the lowest proportion at subsequent marital durations.

One potential source of transformation in first birth patterns over time is the change in marriage cohort composition, reflecting new historical conditions. Table 1 illustrates how successive marriage cohorts of women have moved towards higher education, lower religiosity, smaller families of origin, and increasing labour force participation 


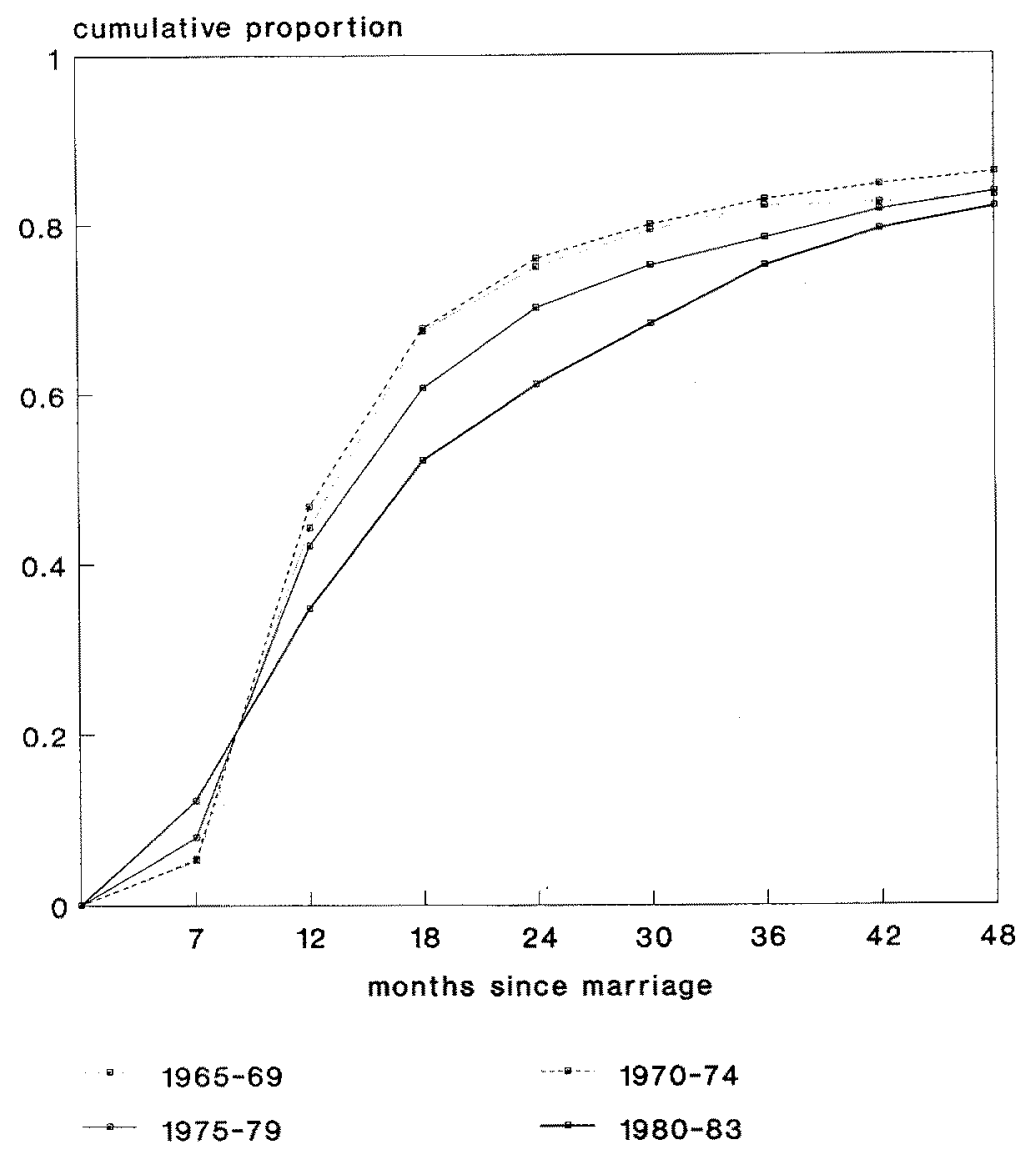

Note: life-table estimates.

Fig. 2. Cumulative proportion of women having a first birth by marital duration for successive marriage cohorts.

before marriage. ${ }^{1}$ All these characteristics have an important impact on the timing of first birth. Life table estimates of the cumulative proportion of women entering motherhood by sociodemographic characteristics in Table 2 indicate that late age at marriage, high educa-

${ }^{1}$ The recent trend towards later age at marriage is not reflected in this distribution, presumably because of the censored experience of young birth cohorts. It is also puzzling that this distribution does not reflect the societal trend towards urbanization. It might be due to having restricted the definition of urban to cities over 100,000 . 
Table 1

Percentage distribution of women by sociodemographic characteristics: marriage cohorts 19651983

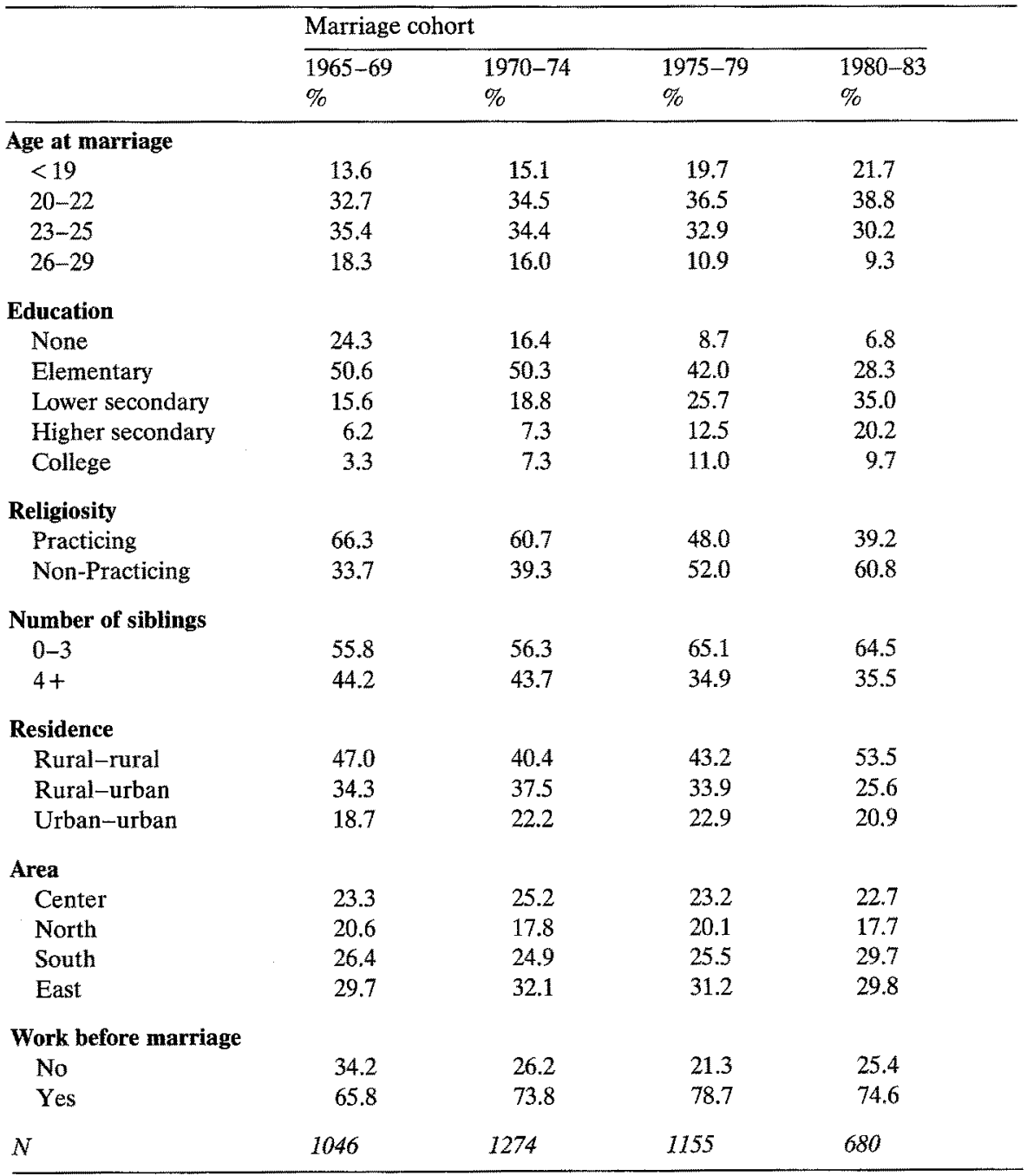

tion, low religiosity, small family size, urban residence and work experience before marriage all lead to the postponement of first birth.

In order to assess the underlying trend in first birth timing, we proceed with the multivariate analysis, which allows us to estimate the 
Table 2

Life table estimates of the cumulative proportion of women having a first birth at successive marital durations

\begin{tabular}{|c|c|c|c|c|}
\hline & \multicolumn{3}{|c|}{ Marital duration } & \multirow{2}{*}{$\begin{array}{l}\text { Median } \\
\text { duration } \\
\text { (months) }\end{array}$} \\
\hline & 7 months & 2 years & 4 years & \\
\hline Total & 0.14 & 0.71 & 0.84 & 13.6 \\
\hline \multicolumn{5}{|l|}{ Marriage cohort } \\
\hline $1965-69$ & 0.09 & 0.75 & 0.83 & 12.9 \\
\hline $1970-74$ & 0.10 & 0.76 & 0.86 & 12.5 \\
\hline $1975-79$ & 0.16 & 0.70 & 0.84 & 13.9 \\
\hline $1980-83$ & 0.21 & 0.61 & 0.82 & 17.0 \\
\hline \multicolumn{5}{|l|}{ Age at marriage } \\
\hline$<19$ & 0.36 & 0.78 & 0.88 & 11.1 \\
\hline $20-22$ & 0.13 & 0.72 & 0.84 & 13.6 \\
\hline $23-25$ & 0.05 & 0.67 & 0.80 & 14.8 \\
\hline $26-29$ & 0.07 & 0.71 & 0.84 & 13.9 \\
\hline \multicolumn{5}{|l|}{ Education } \\
\hline None & 0.16 & 0.80 & 0.88 & 12.0 \\
\hline Elementary & 0.13 & 0.75 & 0.86 & 12.8 \\
\hline Lower secondary & 0.16 & 0.68 & 0.82 & 14.5 \\
\hline Higher secondary & 0.14 & 0.63 & 0.78 & 16.7 \\
\hline College & 0.07 & 0.57 & 0.76 & 18.8 \\
\hline \multicolumn{5}{|l|}{ Religiosity } \\
\hline Practicing & 0.12 & 0.75 & 0.86 & 12.7 \\
\hline Non-practicing & 0.16 & 0.67 & 0.81 & 14.7 \\
\hline \multicolumn{5}{|l|}{ Number of siblings } \\
\hline $0-3$ & 0.12 & 0.69 & 0.82 & 14.3 \\
\hline $4+$ & 0.16 & 0.74 & 0.86 & 12.6 \\
\hline \multicolumn{5}{|l|}{ Residence } \\
\hline Rural-rural & 0.16 & 0.73 & 0.83 & 13.0 \\
\hline Rural-urban & 0,13 & 0.73 & 0.84 & 13.2 \\
\hline Urban-urban & 0.11 & 0.64 & 0.83 & 15.7 \\
\hline \multicolumn{5}{|l|}{ Area } \\
\hline Center & 0.09 & 0.71 & 0.83 & 13.5 \\
\hline North & 0.18 & 0.70 & 0.83 & 13.9 \\
\hline South & 0.16 & 0.77 & 0.88 & 12.3 \\
\hline East & 0.12 & 0.67 & 0.81 & 15.1 \\
\hline \multicolumn{5}{|l|}{ Work before marriage } \\
\hline No & 0.17 & 0.77 & 0.86 & 12.3 \\
\hline Yes & 0.12 & 0.69 & 0.83 & 14.2 \\
\hline
\end{tabular}

$(N=41.55)$ 
change in rates, net of compositional factors. Table 3 presents hazard estimates of the relative risks of entry into motherhood for successive marriage cohorts. If we compare the bivariate estimates (observed differentials) and Model A (net differentials) we note that, once the background variables are taken into account, the rate differential between the 1965-69 marriage cohort and the 1970-74 marriage cohort becomes statistically significant, indicating a slight acceleration in the transition to first birth in the early 1970s. On the other hand, the lengthening of the first interval previously observed for the 1975-79 marriage cohort is no longer significant in the multivariate model. We also observe that the pattern of first birth postponement displayed by the 1980-83 marriage cohort remains substantial even after controlling for compositional factors: the risk of transition to motherhood is $18 \%$ lower than for the preceding cohort.

Recent trends in first interval length can be viewed as the outcome of two opposing processes: on one hand, the increasing number of premaritally conceived births, which leads to an increase in shorter intervals; on the other hand, the increasing postponement of maritally conceived first births, which leads to an increase in longer intervals. The interplay of these two processes and the relative weight of premaritally and maritally conceived births will determine the observed first interval length.

The period under study has witnessed a steady rise in premarital pregnancies. While 9\% of first births for the 1965-69 marriage cohort were premaritally conceived, this proportion doubled for the most recent cohort. This change in the composition of first births is partly offsetting the trend towards first interval lengthening associated with the postponement of maritally conceived births. It also explains why averaging measures, such as median interval length, provide a poor description of the actual evolution of first interval dynamics. In order to isolate these two components, Model B (Table 3) excludes women with premarital pregnancies. This model suggests that the most recent marriage cohort would have had a much more accentuated pattern of first birth delay relative to previous cohorts, were their level of premarital pregnancy similar.

The substantive distinction between premaritally and maritally conceived first births can be appropriately captured in a discrete-time hazard model that incorporates the interaction between marriage cohort and duration segment. Fig. 3 depicts the profile of the transi- 
Table 3

Hazard estimates of the effects of sociodemographic characteristics on first birth timing: relative risks

\begin{tabular}{|c|c|c|c|c|c|c|}
\hline & \multicolumn{2}{|c|}{$\begin{array}{l}\text { Observed } \\
\text { relative risks }\end{array}$} & \multicolumn{2}{|c|}{$\begin{array}{l}\text { Model A } \\
\text { (Model with } \\
\text { premarital } \\
\text { conceptions) }\end{array}$} & \multicolumn{2}{|c|}{$\begin{array}{l}\text { Model B } \\
\text { (Model w/o } \\
\text { premarital } \\
\text { conceptions) }\end{array}$} \\
\hline & $e(\beta)$ & $z(\beta)$ & $\overline{e(\beta)}$ & $z(\beta)$ & $\overline{e(\beta)}$ & $z(\beta)$ \\
\hline \multicolumn{7}{|l|}{ Marriage cohort } \\
\hline $1965-69$ & 1.00 & & 1.00 & & 1.00 & \\
\hline $1970-74$ & 1.04 & $(1.0)$ & 1.09 & (1.9) & 1.10 & (1.9) \\
\hline $1975-79$ & 0.91 & $(-2.0)$ & 1.01 & $(0.1)$ & 0.93 & $(-1.4)$ \\
\hline $1980-83$ & 0.74 & $(-5.3)$ & 0.83 & $(-3.1)$ & 0.68 & $(-5.7)$ \\
\hline \multicolumn{7}{|l|}{ Age at marriage } \\
\hline$<19$ & 1.00 & & 1.00 & & 1.00 & \\
\hline $20-22$ & 0.80 & $(-4.3)$ & 0.86 & $(-2.9)$ & 1.15 & (2.2) \\
\hline $23-25$ & 0.70 & $(-6.9)$ & 0.76 & $(-5.2)$ & 1.10 & (1.5) \\
\hline $26-29$ & 0.73 & $(-5.1)$ & 0.75 & $(-4.6)$ & 1.05 & $(0.7)$ \\
\hline \multicolumn{7}{|l|}{ Education } \\
\hline None & 1.00 & & 1.00 & & 1.00 & \\
\hline Elementary & 0.88 & $(-2.4)$ & 0.94 & $(-1.1)$ & 0.95 & $(-0.9)$ \\
\hline Lower secondary & 0.78 & $(-4.1)$ & 0.90 & $(-1.7)$ & 0.87 & $(-2.1)$ \\
\hline Higher secondary & 0.69 & $(-5.2)$ & 0.83 & $(-2.4)$ & 0.80 & $(-2.6)$ \\
\hline College & 0.59 & $(-6.7)$ & 0.71 & $(-4.0)$ & 0.71 & $(-3.7)$ \\
\hline \multicolumn{7}{|l|}{ Religiosity } \\
\hline Practicing & 1.00 & & 1.00 & & 1.00 & \\
\hline Non-practicing & 0.85 & $(-4.8)$ & 0.90 & $(-2.8)$ & 0.86 & $(-3.6)$ \\
\hline \multicolumn{7}{|l|}{ Number of siblings } \\
\hline $0-3$ & 1.00 & & 1.00 & & 1.00 & \\
\hline $4+$ & 1.15 & $(4.0)$ & 1.08 & (2.1) & 1.07 & (1.7) \\
\hline \multicolumn{7}{|l|}{ Residence } \\
\hline Rural-rural & 1.00 & & 1.00 & & 1.00 & \\
\hline Rural-urban & 0.97 & $(-0.7)$ & 1.02 & $(0.4)$ & 1.01 & $(0.2)$ \\
\hline Urban-urban & 0.86 & $(-3.3)$ & 0.98 & $(-0.4)$ & 0.99 & $(-0.1)$ \\
\hline \multicolumn{7}{|l|}{ Area } \\
\hline Center & 1.00 & & 1.00 & & 1.00 & \\
\hline North & 1.01 & $(0.1)$ & 0.99 & $(-0.3)$ & 0.90 & $(-1.9)$ \\
\hline South & 1.18 & $(3.4)$ & 1.09 & $(1.8)$ & 1.09 & (1.6) \\
\hline East & 0.89 & $(-2.3)$ & 0.91 & $(-1.8)$ & 0.88 & $(-2.4)$ \\
\hline \multicolumn{7}{|l|}{ Work before marriage } \\
\hline No & 1.00 & & 1.00 & & 1.00 & \\
\hline Yes & 0.85 & $(-4.4)$ & 0.92 & $(-2.2)$ & 0.96 & $(-1.0)$ \\
\hline
\end{tabular}


Table 3 (continued)

\begin{tabular}{|c|c|c|c|c|c|c|}
\hline & \multicolumn{2}{|c|}{$\begin{array}{l}\text { Observed } \\
\text { relative risks }\end{array}$} & \multicolumn{2}{|c|}{$\begin{array}{l}\text { Model A } \\
\text { (Model with } \\
\text { premarital } \\
\text { conceptions) }\end{array}$} & \multicolumn{2}{|c|}{$\begin{array}{l}\text { Model B } \\
\text { (Model w/o } \\
\text { premarital } \\
\text { conceptions) }\end{array}$} \\
\hline & $\overline{e(\beta)}$ & $z(\beta)$ & $\overline{e(\beta)}$ & $z(\beta)$ & $\overline{e(\beta)}$ & $z(\beta)$ \\
\hline \multicolumn{7}{|l|}{ Duration segment } \\
\hline $0-7$ months & 0.25 & $(-23.5)$ & 0.24 & $(-24.2)$ & & \\
\hline $8-12$ & 1.64 & $(10.7)$ & 1.60 & $(10.1)$ & 1.58 & $(9.8)$ \\
\hline $13-18$ & 1.00 & & 1.00 & & 1.00 & \\
\hline $19-24$ & 0.67 & $(-5.9)$ & 0.68 & $(-5.8)$ & 0.67 & $(-5.8)$ \\
\hline $25-36$ & 0.45 & $(-11.5)$ & 0.46 & $(-11.5)$ & 0.45 & $(-11.5)$ \\
\hline $37-48$ & 0.23 & $(-14.5)$ & 0.23 & $(-14.6)$ & 0.22 & $(-14.8)$ \\
\hline$N$ (person-segments) & & & \multicolumn{2}{|c|}{13225} & \multicolumn{2}{|c|}{12705} \\
\hline
\end{tabular}

tion to motherhood for successive marriage cohorts based on piecewise constant hazard estimates. As previously discussed, the 1980-83 cohort displays the highest rates of childbearing during the first seven months of marriage, reflecting a larger incidence of premarital conceptions, but once premaritally pregnant women are removed from risk, it exhibits substantially lower rates of transition to first birth up to the second year of marriage. After this marital duration, the rates of transition are again higher than in the preceding cohorts, suggesting that initially postponed births are "made up" in the third and fourth year of marriage.

In sum, the timing pattern of transition to first birth has recently undergone a considerable transformation. The marriage cohorts of the late 1960 s and early 1970 s maintained an almost static pattern of family formation. Most of the women in these cohorts had their first child right after marriage, reflecting the prevailing linkage between women's marital status and motherhood role. However, a pattern of delayed childbearing emerges in the mid-1970s, and becomes especially manifest in the 1980s: half of the women in this last marriage cohort who were not pregnant at marriage postponed their first birth beyond the second year of marriage. At the same time, the incidence of out-of-wedlock pregnancy, precipitated marriage and subsequent rapid childbearing has increased substantially among younger cohorts. This latter pattern has partly offset the aggregate trend towards first interval lengthening. 


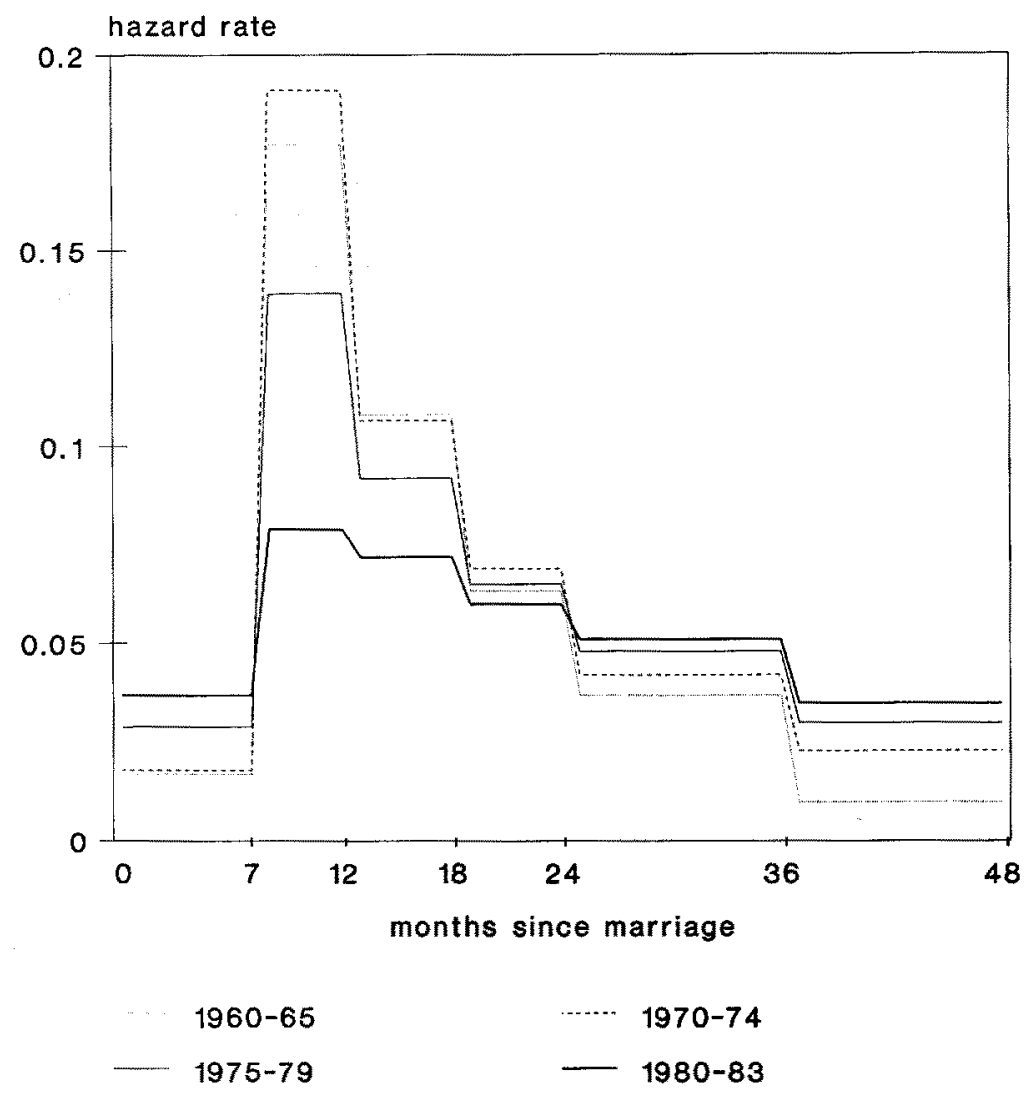

Control variables: age at marriage,

education, religiosity, siblings,

urban, region and work experienoe.

Fig. 3. First birth hazard rates for successive marriage cohorts.

The change in contraceptive use patterns has undoubtedly played a major role in the evolution of first birth timing. The period examined coincides with the transition from a primitive contraceptive regime to a modern one (Linhard, 1983), since it was not until 1979 that the ban on contraception was removed and access to modern methods became widespread.

Consistent with the trend of first interval lengthening previously described, Table 4 shows a dramatic increase in contraceptive use since 1975 . While only $8 \%$ of the women married in the late $1960 \mathrm{~s}$ 
Table 4

Prevalence of contraceptive use in first birth interval and distribution of contraceptive method used, for successive marriage cohorts

\begin{tabular}{|c|c|c|c|c|}
\hline & \multicolumn{4}{|c|}{ Marriage cohort } \\
\hline & $\begin{array}{l}1965-69 \\
\%\end{array}$ & $\begin{array}{l}1970-74 \\
\%\end{array}$ & $\begin{array}{l}1975-79 \\
\%\end{array}$ & $\begin{array}{l}1980-83 \\
\%\end{array}$ \\
\hline \multicolumn{5}{|c|}{ Contraceptive use } \\
\hline None & 92.0 & 86.8 & 74.4 & 58.9 \\
\hline Ineffective & 5.4 & 5.7 & 6.5 & 8.4 \\
\hline Effective & 2.6 & 7.5 & 19.1 & 32.7 \\
\hline \multicolumn{5}{|c|}{ Method employed by users } \\
\hline Pill & 20.3 & 44.7 & 59.9 & 48.9 \\
\hline IUD & 0.0 & 2.4 & 0.6 & 5.6 \\
\hline Diaphragm & 0.0 & 0.0 & 0.6 & 0.0 \\
\hline Condom & 11.4 & 9.4 & 12.7 & 24.1 \\
\hline Rhythm & 16.5 & 15.3 & 9.7 & 8.0 \\
\hline Withdrawal & 49.4 & 27.1 & 12.5 & 9.6 \\
\hline Other & 2.4 & 1.1 & 4.0 & 3.8 \\
\hline
\end{tabular}

Note: Pill, IUD, condom and diaphragm are classified as efficient methods; rhythm and withdrawal as inefficient methods.

regulated their fertility after marriage, $41.1 \%$ of the women married in the early 1980 s used contraception in order to delay their first child. Not only has the proportion of women using birth control increased, but a substantial shift towards efficient methods has occurred. The pill has gradually replaced withdrawal as the leading means of contraception.

In sum, only in recent times have Spanish women been able to control reliably their fertility. Though birth control is not a new phenomenon, the ambiguous legal status of contraceptives imposed substantial constraints on earlier marriage cohorts. Low availability of contraception interacted with strong normative pressures to start family building right after marriage. This situation changed in the late 1970 s, owing to the increasing availability and social acceptability of effective contraceptive methods. It is within this modern contraceptive regime that women have started to delay their first birth.

\section{Differentials in the timing of transition to first birth}

Having established evidence of the current pattern of delayed childbearing, we will next address the socio-demographic factors that 
Table 5

Test for interactions between covariates and duration segments: piecewise constant hazard models

\begin{tabular}{lllrrl}
\hline & $\begin{array}{l}-2 \log \\
\text { likelihood }\end{array}$ & d.f. & $\chi^{2}$ & d.f. & p \\
\hline Baseline & 13797 & 13201 & & & \\
Marr Cohort*Duration & 13626 & 13186 & 171 & 15 & $<0.005$ \\
Age at Marr*Duration & 13559 & 13186 & 238 & 15 & $<0.005$ \\
Education*Duration & 13739 & 13181 & 58 & 20 & $<0.005$ \\
Religiosity* Duration & 13752 & 13196 & 45 & 5 & $<0.005$ \\
Siblings*Duration & 13794 & 13196 & 3 & 5 & $>0.10$ \\
Residence*Duration & 13763 & 13191 & 34 & 10 & $<0.005$ \\
Area* Duration & 13745 & 13186 & 52 & 15 & $<0.005$ \\
Work bef marr *Duration & 13786 & 13196 & 11 & 5 & $<0.05$ \\
\hline
\end{tabular}

Note: The Baseline Model assumes additive effects of all the covariates.

influence the postponement of motherhood. In this section, we will analyze the timing of transition to first birth as a function of women's age at marriage, education, religiosity, size of family of origin, type of residence, geographical area and work experience before marriage. Parallel analyses for all women and for women with no premarital pregnancies will be conducted, in order to identify which variables influence first interval length mainly through their effect on the probability of premarital conception.

The test for interactions between covariates and duration segments in Table 5 suggests that the effect of all variables, except number of siblings, changes with marital duration. Accordingly, we will discuss the overall impact of each covariate and its changing effect across duration. To facilitate interpretation, we will plot the duration-specific hazard rates for the most relevant variables.

\section{Age at marriage}

Though age at marriage is obviously connected to age at first birth, the relationship between age at marriage and speed of transition to motherhood is not as clear-cut. There are a number of reasons to expect a positive association between age at marriage and first birth postponement. Women who delay marriage are likely to have more education and longer labour force experience, compositional factors that will also lead to the postponement of their first birth. Further- 
more, they are likely to be selected in terms of less traditional attitudes towards childbearing and gender roles. Even if there were not a selection process in terms of composition and personal traits, the waiting time to entry into marriage is likely to have an effect in itself, via longer exposure to life styles not centered around the family and via experience in contraceptive use.

On the other hand, it is also plausible to envision an effect of age at marriage in the opposite direction. Among women who marry late, marriage and motherhood might be the outcome of a joint decision, and therefore be closely timed. Also, though the biological constraints of age-graded fecundity are unimportant at this early stage of family formation, the social dimension of age (Rindfuss and Bumpass, 1978) is likely to affect childbearing timing intentions. Late marriers may speed up the process of family formation in order to "catch up" with their peers in terms of life cycle stage.

Though there are legitimate reasons to expect positive and negative effects of age at marriage on first interval length, empirical evidence strongly supports the association of late marriage and late onset of childbearing. However, a confounding factor in this relationship is the association of early marriage and premarital pregnancy. In this sample, for example, $36 \%$ of the teenage brides were pregnant at marriage, but this was the case for only $7 \%$ of the women married after age 26. Consequently, we need to examine whether shorter intervals among young marriers are due primarily to the process of legitimation of premarital pregnancies.

Life table results (Table 2) indicate very large differentials in the first seven months of marriage according to age of entry into union, and a narrowing gap later on. In the multivariate model (Table 3, Model A), the inverse relationship between age at marriage and speed of transition to motherhood remains practically unaltered after controls are applied, indicating that this association can not be explained by the background variables included in the model. However, when women with premarital pregnancies are excluded (Table 3, Model B), the inverse association disappears, and women who enter marriage at ages 20 to 22 display even higher transition rates than women married during their teens.

Fig. 4 illustrates the changing effect of age at marriage across marital duration. The graph supports the interpretation above: differentials in the rate of entry into motherhood are concentrated in the 


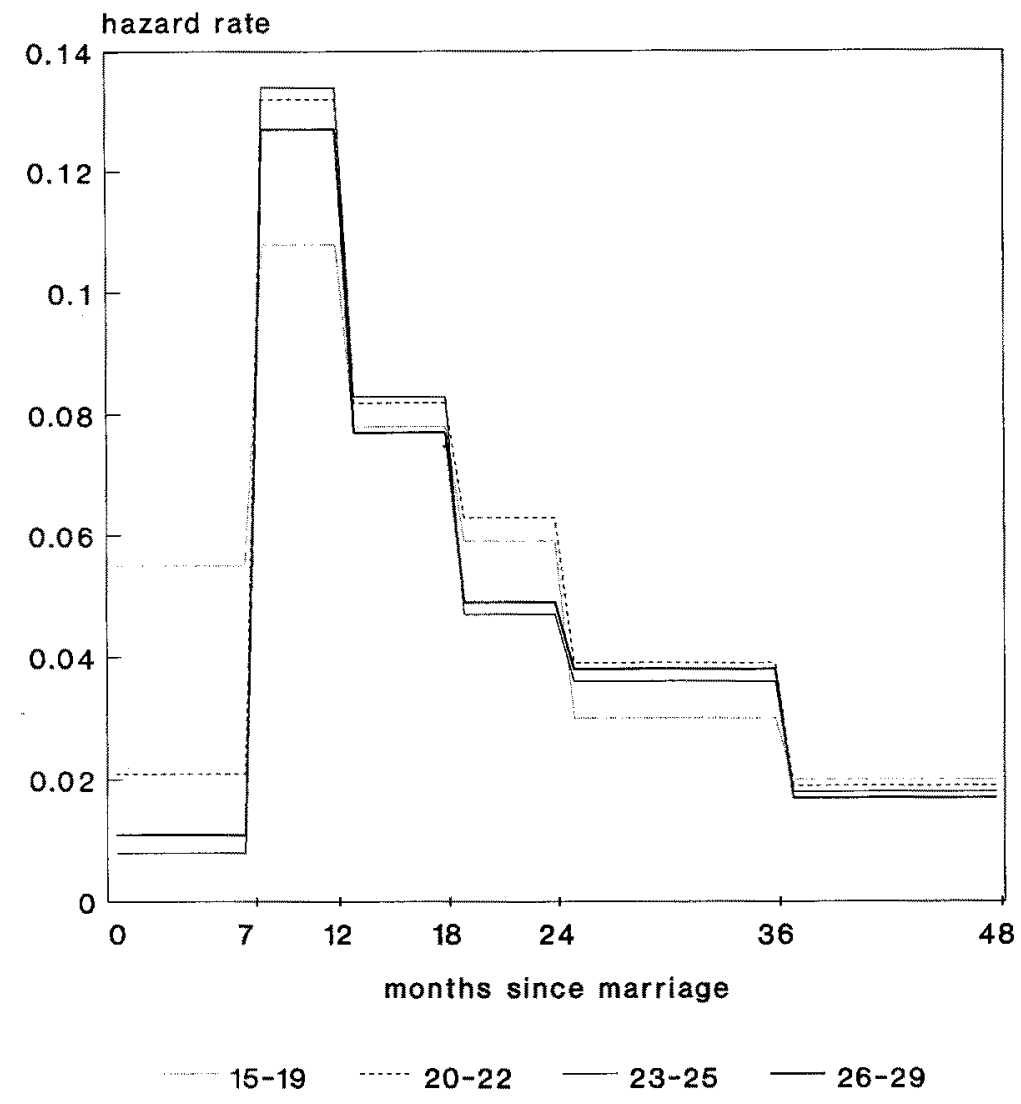

Control varlables: marriage cohort education, rellgloslly, slblings,

urban, region and work experience.

Fig. 4. First birth hazard rates according to age at marriage.

first duration segment ( 0 to 7 months), which corresponds to premaritally conceived births. In the second segment ( 8 to 12 months), which represents the typical waiting time to first birth for women who are not using contraception, all age groups have higher rates than the youngest age group. After that duration, differentials become relatively small, and they disappear completely after three years of marriage.

Based on this evidence, we can conclude that the effect of age at marriage on first birth timing reflects primarily the impact of premari- 
tal conceptions on shortening the first interval. For women who are not pregnant at the wedding, age at marriage does not seem to have a genuine influence on their pace of childbearing.

\section{Education}

Education has always been a central variable in the sociological and economic literature of fertility (Cochrane, 1983). Women's education is assumed to increase the opportunity cost of the tradeoff between domestic and formal labour market roles (Becker, 1981). Education is also regarded as connected to less traditional gender role models and to aspirations that compete with childbearing (Blake and Del Pinal, 1980). Moreover, fertility preferences are considered to be better implemented by educated women through effective use of birth control.

This array of mechanisms (child cost, family size preferences and contraceptive efficacy) refers to the linkage between education and completed fertility, and does not necessarily apply to the birth interval level. An illustrative example of noncorrespondence between the aggregate fertility level and the birth interval level is the pattern of closer spacing of first and second births found among educated women in many developed societies (e.g. Ní Bhrolcháin, 1988). The expected effect of education on first interval length has an ambivalence similar to that of age at marriage. If education stands as an indicator of attachment to the labour force and as a proxy for taste for non-familial roles, we should find a positive association between educational level and first birth delay. However, it is also plausible that most of the influence of non-traditional attitudes is already captured by marriage postponement, and that once the process of family formation is started, educated women choose to proceed quickly from childlessness to motherhood.

Life table results in Table 2 suggest the existence of substantial differentials in the pace of first birth transition by level of education attained. ${ }^{2}$ While $80 \%$ of the women with no education have made the transition to first birth within two years of marriage, only $57 \%$ of the

\footnotetext{
${ }^{2}$ Since only education at the time of interview was recorded, we have to assume that educational attainment did not change significantly after marriage. Also, though causality may run in both directions (Marini, 1984), we will assume that causation flows mainly from education to fertility. The assumption of no reciprocal effects should be taken with caution for the youngest ages, since the arrival of the first child may plausibly halt school continuation.
} 
women with a college degree have become mothers in the same time span. Differentials become attenuated at longer durations of marriage, but still persist after four years.

The multivariate model (Table 3, Model A) reveals that differentials among the three lower educational categories disappear once other compositional factors are controlled for. The pattern of longer first birth postponement persists, though attenuated, for the two upper educational categories (higher secondary and college). In addition, we note that educational effects are not mediated by premarital work experience. This might suggest that the effect of education goes beyond opportunity cost concerns, and might be related to values and attitudes that discourage early fertility within marriage. Educated women may be more likely to deliberately plan a child-free period to consolidate not only their position in the market but also their marital relationship.

With regard to the change in the effect of education throughout marital duration, Fig. 5 shows that differentials in the pace of childbearing among educational groups are not due to unequal levels of premarital pregnancy (hazard rates are all very similar in the first seven months of marriage). Variation in rates is mainly concentrated in durations 8 to 18 months, suggesting that educational differentials could plausibly be attributed to unequal proportions of contraceptive users across educational groups. Differentials become attenuated with increasing marital duration, and for college graduates we observe a "catching up" pattern after the second year of marriage.

\section{Labour force participation before marriage}

The impact of women's labour force participation on fertility has received considerable attention in the literature (Sweet, 1981; Bernhardt, 1989). Given the existing conflict between mother and worker roles, resulting from the gender-based division of labour that persists in contemporary societies, work status is probably the variable with the most potential for influencing first birth timing.

The 1985 Spanish Fertility Survey provides information on women's work status before the first child, but no dates of entry and exit from the labour force. Given the existence of reciprocal causality (Cramer, 1980), and the lack of detailed work histories, which would have permitted us to treat labour force activity as a time-varying covariate, 

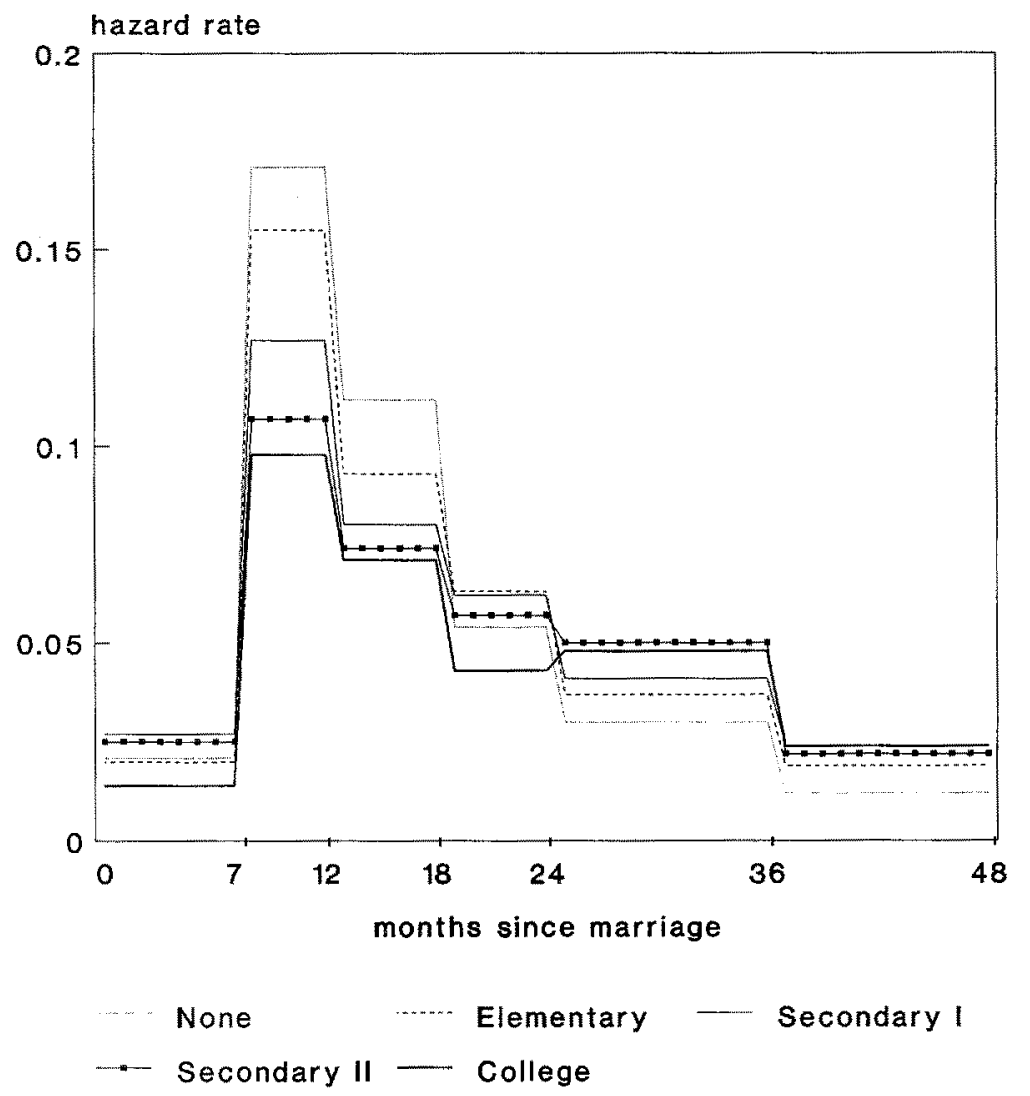

Fig. 5. First birth hazard rates for educational groups.

we have not used the work information pertaining to the birth interval under study. We have, however, examined the impact of work experience before marriage, a fixed characteristic for all women at the initiation of exposure. This variable cannot elucidate the causal complexity between women's work and first birth timing since they refer to different time frames. Nevertheless, we expect employment status before marriage to reflect women's orientations towards gender roles and to be correlated with work status at the time of exposure. 
Life table results (Table 2) indicate that women with labour force experience have a lower rate of transition to first birth at all durations, though the differential is not very large. Multivariate relative risks (Table 3, Model A) suggest that the negative association remains after controlling for compositional characteristics. However, when women with premarital pregnancies are excluded (Table 3, Model B), the effect of working experience becomes statistically nonsignificant. This result suggests that women out of the labour force are more likely to become premaritally pregnant and thus influence the overall first interval length with their early births. For women who are not pregnant at the time of marriage, however, labour force experience before marriage does not affect the speed of transition to motherhood.

\section{Religiosity}

Religious attitudes may play an important role in structuring the process of family formation through various mechanisms. On one hand, strict observance of Catholic precepts on reproduction is assumed to deter birth control use, especially use of efficient methods, and therefore to enhance the likelihood that a woman has her first child right after marriage. Also, besides pronatalist values and contraceptive proscription, religiosity is assumed to be linked to family oriented attitudes and traditional gender role ideals. On the other hand, religious women may be less likely to contribute shorter intervals by means of premarital pregnancies, given the Church's emphasis on prenuptial sexual chastity.

Life table results (Table 2) indicate a more rapid pace of childbearing for those women who identified themselves as religious, except in the first seven months of marriage, where we find the reverse relationship. This pattern indicates that religious practice is associated with lower risks of premarital pregnancy, but a faster pace of marital childbearing, presumably reflecting a lower usage of contraception. These differentials remain in the multivariate model (Table 3, Model A) after controlling for the other background variables.

\section{Number of siblings}

The size of a woman's family of origin might influence her fertility and, consequently, the timing of her first birth, via intergenerational 
transmission of childbearing norms. On the other hand, the association of reproductive patterns across generations might be partly attributable to compositional factors such as education, a scarcer resource among members of large families.

Bivariate results from life tables (Table 2) and hazard models (Table 3) suggest that daughters raised in larger families have a more rapid pace of transition to first birth. Specifically, women with four or more siblings have an observed childbearing rate $15 \%$ higher than women from smaller families. Multivariate results (Table 3, Model A) show that those differentials remain even after controls for education and age at marriage are established, though they are attenuated. When women with premarital pregnancies are excluded (Table 3, Model B), the coefficient corresponding to parental family size becomes statistically insignificant. This result suggests that the differentials observed in the pace of childbearing can be attributed to the higher likelihood of premarital pregnancy among women brought up in larger families.

\section{Rural / urban residence}

Living in an urban setting is assumed to have a negative impact on fertility through an array of factors, such as higher costs of childbearing, broaden opportunities for paid employment, modern values and better access to birth control. The same type of relationship is presumed to hold for the first birth interval. In rural areas, where educational and labour market opportunities are limited and where it is easier to combine non-domestic work (paid or unpaid) and family obligations, early motherhood may be perceived as more attractive.

Since the survey provides information on residence at childhood and current residence, we have cross-tabulated these two variables. (Since only a very small proportion of women moved from urban to rural areas, this category is collapsed with permanent urban residence). Though the official definition of urban applies to any settlement over 10,000 population, this analysis classifies as urban only those settlements over 100,000 , in order to capture "urban life styles" in a more realistic way.

As expected, life table estimates (Table 2) show that women who have lived in urban areas during both their childhood and adult years have a slower pace of transition to motherhood than the rest of the 
women. However, there is practically no difference between women in rural areas and those who migrated from rural to urban areas. All differentials according to type of residence disappear in the multivariate model (Table 3, Model A), suggesting that the divergence in first birth timing between urban and rural dwellers is mainly attributable to their distinct socio-demographic composition.

The finding of nonsignificant effect for urban residence was against our expectations. However, previous studies of Spanish fertility based on the 1977 wFs also found very small differences between rural and urban areas (Jones, 1982).

\section{Region}

Spain can be appropriately described as a mosaic of distinct cultures. The diversity of nuptiality and fertility patterns has been a constant throughout history (Leasure, 1963; Livi Bacci, 1968; Reher, 1991). Therefore, regional differentials should be incorporated into the analysis, since it might be misleading to draw conclusions based only on national averages.

An exploratory analysis revealed that the pace of transition to first birth varies substantially by region. ${ }^{3}$ The most developed areas, such as Madrid, Cataluña and País Vasco, all follow an obvious pattern of first birth delay. In order to simplify the presentation, we grouped the 17 regions into four large areas: North, South, Centre and East. ${ }^{4}$ This grouping, based on a geographical criterion, is somewhat arbitrary. It may conceal internal differences in terms of economic environment and cultural heritage, but it will capture some regional variability.

The observed pattern is one of rapid transition to first birth in the South and slower transition in the East compared to the Center, the reference region (Table 3 ). These differentials may represent cultural and normative variations on the ideal timing of childbearing. They

\footnotetext{
${ }^{3}$ Unfortunately, region of residence at the time of interview is the only information available. The region where the woman was born would be more relevant, since it usually represents the cultural context she identifies with.

${ }^{4}$ The grouping is done as follows: Centre includes Castilla-León, Castilla-la Mancha, Madrid and Rioja; North includes Galicia, Asturias, Cantabria, País Vasco and Navarra; South includes Extremadura, Andalucía, Murcia and Canarias; and East includes Cataluña, Aragón, Valencia and Baleares.
} 
may also represent unmeasured structural differences in regional socio-economic settings.

The differentials remain, though highly attenuated, in the multivariate analysis (Table 3, Model A). When premarital pregnancies are excluded (Table 3, Model B), the pattern of differentials changes, and the Northern region together with the Eastern region displays a slower pace of transition to first birth.

\section{Summary and conclusions}

Spain has experienced a sharp acceleration in the secular process of fertility decline during recent years (the total fertility rate went from 2.7 in 1975 to 1.3 in 1990). This drastic reduction of fertility coincided with the transition to a democratic political context, the legalization of contraceptives, an economic environment characterized by high levels of youth unemployment and a considerable liberalization in the values and norms governing family behaviour and gender roles. Substantial changes in the process of family building have also taken place during this period. Among them, the postponement of marriage, the delay of first births, the longer spacing of second births and the lower rate of transition to third births (Castro Martin, 1990). Owing to the confluence of tempo and quantum changes, period measures such as total fertility rates are probably underestimating the reproductive performance of young cohorts, and the 1990s "baby bust" can be partly attributed to the recent aging of the fertility pattern.

This study has focused on the onset of the reproductive process: the transition to first birth, whose timing can significantly affect the societal level of reproduction. Our results showed a pattern of rapid family formation during the $1960 \mathrm{~s}$ and the $1970 \mathrm{~s}$. The most recent marriage cohort, however, was found to follow an innovative family building strategy, characterized by postponing the arrival of the first child. We also documented a dramatic increase in the incidence of premarital conceptions, presumably reflecting more permissive sexual mores, which partly offset the recent trend towards first interval lengthening. Coinciding in time, we found a dramatic increase in birth control use among recent cohorts. Despite the existence of considerable differentials in the timing of transition to first birth, we found little variation with respect to becoming a mother. Consequently, 
effects detected at short marital durations disappeared at longer durations, or even reversed, as delayers "caught up" in the childbearing process.

Though the pattern of first birth postponement has been observed in most industrialized countries during the last two decades (e.g. Wilkie, 1981; Bloom, 1984; Khoo and Krishnamoorthy, 1985; Teachman and Polonko, 1985; Rindfuss et al., 1988; Loh and Ram, 1990; Chen and Morgan, 1991), this is a genuinely new phenomenon in Spain. This innovative pattern can be viewed as the outcome of a number of confluent factors. Early family formation is especially sensitive to changing social and economic conditions, since this life cycle stage coincides with the time normatively prescribed for choosing a permanent residence, securing a job and buying a home. Unstable economic conditions may encourage young couples to postpone childbearing until some reasonable security is achieved. Since in a modern contraceptive regime, motherhood may be more easily shifted than educational and occupational roles, women may opt to delay their first child until their non-familial roles are consolidated. There has also been a profound change in the cultural norms that define the "appropriate" time for childbearing, mainly as a response to other life course changes such as delayed marriage, increased women's education and labour force participation, allowing more women's control over their life course.

In sum, most societal trends have led to an increasing dissociation of marriage and motherhood in Spain. Recent cohorts no longer regard motherhood as a transition that occurs naturally right after marriage. The access to effective birth control makes it possible to follow a planned strategy of family building, and the anticipation of a small family allows for a broad range of timing options. The timing chosen is most likely aimed at synchronizing non-family and family roles in an optimal way.

\section{Acknowledgements}

Comments and suggestions from Larry L. Bumpass are gratefully acknowledged, as well as research support from the Center for Demography and Ecology at the University of Wisconsin-Madison and financial support from the Spanish Ministry of Education. 


\section{References}

Agüero, I. and Olano, A $x$ 1980. La evolución reciente de la fecundidad en España. Revista Española de Investigaciones Sociológicas, 10: 121-150.

Aitkin, M. and Clayton, D., 1980. The fitting of the exponential, weibull and extreme value distributions to complex censored survival data using GLIM. Applied Statistics, 29: 156-163.

Alcobendas, P., 1984. The employment of women in Spain. Commission of the European Communities, Luxembourg.

Allison, P.D., 1982. Discrete-time methods for the analysis of event histories. In: S. Leinhardt, ed. Sociological Methodology 1982. Jossey-Bass, San Francisco, CA: 61-98

Arango, J., 1987. La modernización demográfica de la sociedad española. In: J. Nadal, A. Carreras and C. Sudrià, eds. La economía española en el siglo XX: una perspectiva histórica. Ariel, Barcelona: 201-236.

Baker, R.J. and Nelder, J.A., 1978, The GLIM-system, Release 3. Numerical Algorithms Group, Oxford.

Becker, G., 1981. A Treatise on the Family. Harvard University Press, Cambridge, MA.

Bernhardt, E.M., 1989. Fertility and employment. Stockholm Research Reports in Demography No. 55, University of Stockholm.

Blake, J. and Del Pinal, J, 1980. Educational attainment and reproductive preferences: theory and evidence. In: C. Hohn and R. Mackensen, eds. Determinants of Fertility Trends: Theories Re-examined. Ordina Editions for IUSSP, Liège: 59-78.

Blayo, C., 1987. La fécondité en Europe depuis 1960: convergence ou divergence? Plenaries of the European Population Conference 1987. Central Statistical Office of Finland, Helsinki.

Bloom, D.E., 1984. Delayed childbearing in the United States. Population Research and Policy Réview, 3: 103-139.

Bumpass; L.L., Rindfuss, R.R. and Janosik, R., 1978. Age and marital status at first birth and the pace of subsequent fertility. Demography, 15: 75-86.

Castro Martin, T., 1990. Recent patterns of family formation in Spain: a sequential analysis of parity transitions. $\mathrm{PhD}$ dissertation, Department of Sociology, University of Wisconsin-Madison, WI.

Chen, R. and Morgan, P., 1991. Recent trends in first birth timing in the United States. Demography, 28, 523-533.

Cochrane, S., 1983. Effects of education and urbanization on fertility. In: R. Bulatao and R. Lee, eds. Determinants of Fertility in Developing Countries, Vol. 2. Academic Press, New York: $587-626$.

Cox, D.R., 1972. Regression models and life tables. Journal of the Royal Statistical Society, Series B, 34: 187-220.

Cramer, J.C., 1980. Fertility and female employment: problems of causal direction. American Sociological Review, 45: 161-190.

Delgado Pérez, M. and Fernández Cordón, J.A., 1989. La fecundidad en España desde 1975. Documento de Trabajo 2, Instituto de Demografía, Madrid.

Díez Nicolás, J. and de Miguel, J., 1981. Control de natalidad en España. Fontanella, Barcelona.

Feeney, G., 1983. Population dynamics based on birth intervals and parity progressions. Population Studies, 37: 75-89.

Fernández Cordón, J.A., 1986. Análisis longitudinal de la fecundidad en España. Actas del simposio internacional sobre tendencias demográficas y planificación económica, Ministerio de Economía y Hacienda, Madrid: 49-75.

Gilks, W.R., 1986. The relationship between birth history and current fertility in developing countries. Population Studies, 40: 437-455. 
Hicks, W.W. and Martínez-Aguado, T., 1987. Las determinantes de la fecundidad dentro del matrimonio en España. Revista Española de Investigaciones Sociológicas, 39: 195-212.

Hobcraft, J. and Rodríguez, G., 1980. Some methodological issues on life-table analysis of birth histories. Paper presented at the IUSSP seminar on analysis of maternity histories, London.

Hobcraft, J. and Murphy, M., 1986. Demographic event history analysis: a selective review. Population Index, 52: 3-27.

Hoem, J.M., 1985. The impact of education on modern union initiation. Stockholm Research Reports in Demography No. 27, University of Stockholm.

Hoffert, S.L., 1984. Long-term economic consequences for women of delayed childbearing and reduced family size. Demography, $21: 141-155$.

Jones, E.F., 1982. Socio-economic differentials in achieved fertility, WFS Comparative Studies 21, ECE Analysis of WFS Surveys in Europe and USA, International Statistical Institute, Voorburg, Netherlands.

Khoo, S. and Krishnamoorthy, S., 1985. Changes in the timing of births in Melbourne, Australia. Journal of Biosocial Science, 17: 235-247.

Lamas, L., 1985. Birth Intervals, parity-specific fertility and stable populations. PhD dissertation, Department of Sociology, University of Wisconsin-Madison, WI.

Leasure, W., 1963. Factors involved in the decline of fertility in Spain 1900-1950. Population Studies, 16: 271-285.

Linhard, J., 1983. Family planning in Spain. International Family Planning Perspectives, 9: 9-14.

Livi Bacci, M., 1968. Fertility and nuptiality in Spain from the late 18 th to the early 20 th century. Population Studies, 22: 83-102, 211-234.

Loh, S. and Ram, B., 1990. Delayed childbearing in Canada: trends and factors. Genus, 66: $147-161$.

Marini, M.M., 1984. Women's educational attainment and the timing of entry into parenthood. American Sociological Review, 49: 491-511.

Monnier, A., 1990. Actualité démographique européenne. Population et Société No. 250, INED, Paris.

Moreno-Navarro, L., 1987. Fertility change in five Latin American countries: a covariance analysis of birth intervals. Demography, 24: 23-41.

Muñoz-Pérez, F., 1987. Le déclin de la fécondité dans le sud de l'Europe. Population, 6: 911-942.

Namboodiri, K. and Suchindran, C.M., 1987. Life table techniques and their applications. Academic Press, Studies in Population, New York.

Newman, J.L. and McCulloch, C.E., 1984, A hazard rate approach to the timing of births. Econometrica, 52: 939-961.

Ní Bhrolcháin, M., 1988. The contraceptive confidence idea: an empirical investigation. Population Studies, 42: 205-225.

Palloni, A. and Sorensen, A., 1986, Methods for the analysis of event history data. Center for Demography and Ecology Working Paper No. 86-36, Center for Demography and Ecology, University of Wisconsin-Madison, WI.

Reher, D.S., 1991. Marriage patterns in Spain, 1887-1930. Journal of Family History, 16: 7-30.

Rindfuss, R.R. and Bumpass, L.L., 1978. Age and the sociology of fertility: how old is too old? In: K. Taeuber, L. Bumpass and J. Sweet, eds. Social Demography. Academic Press, New York.

Rindfuss, R.R., Palmore, J.A. and Bumpass, L.L., 1982. Selectivity and the analysis of birth intervals from survey data. Asian and Pacific Census Forum, 8: 5-16.

Rindfuss, R.R, Morgan, S.P. and Swicegood, G., 1988. First Births in America: Changes in the Timing of Parenthood. University of California Press, Berkeley, CA. 
Rodríguez, G., Hobcraft, J., McDonald, J., Menken, J. and Trussell, J., 1984. A comparative analysis of birth intervals. WFS Comparative Studies No. 30, International Statistical Institute, Voorburg, Netherlands.

Ryder, N.B., 1980. Components of temporal variations in American fertility. In: R.W. Horns, ed. Demographic Patterns in Developed Societies. Taylor Francis, London: 11-54.

Ryder, N.B., 1982. Progressive fertility analysis. WFS Technical Bulletin No. 8, International Statistical Institute, Voorburg, Netherlands.

Sáez, A., 1979. La fécondité en Espagne depuis le début du siècle. Population, 6: 1007-1022.

Sweet, J.A., 1981. Work and fertility. In: G.L. Fox, ed. The Childbearing Decision. Sage, New York: $197-218$.

Teachman, J.D. and Polonko, K., 1985. Timing of the transition to parenthood: a multidimensional birth-interval approach. Journal of Marriage and the Family, 47: 867-879.

Trussell, J., Martin, L., Feldman, R., Palmore, J., Concepcion M. and Bakar, D., 1985. Determinants of birth interval length in the Philippines, Malaysia and Indonesia: a hazardmodel analysis. Demography, 22: 145-168.

Tsui, A.O., 1982. The family formation process among US marriage cohorts. Demography, 19: 1-28.

Walter, C.A., 1986. The Timing of Motherhood. Lexington Books, Lexington, MA.

Wilkie, J.R., 1981. The trend toward delayed parenthood. Journal of Marriage and the Family, 43: 583-591, 